\title{
Single-Screw Hydraulic Machines in the Oil and Gas Industry: Fields of Application and Development Prospects
}

\author{
Baldenko DF and Baldenko FD* \\ OJSC, NPO Drilling Technics, Russia \\ Russian State University of Oil and Gas, Russia
}

*Corresponding author: Baldenko FD, Russian State University of Oil and Gas, Russia, Email: fbaldenko@mail.ru

\section{Review Article \\ Volume 3 Issue 5}

Received Date: October 09, 2019

Published Date: October 24, 2019

DOI: $10.23880 /$ ppej- 16000207

\section{Abstract}

Next year, the scientific and technical community will celebrate the 90th anniversary of the invention by the prominent French engineer Rene Moineau of the principle of capsulism, which gave rise to the foundations of a new type of volumetric hydraulic machines, which are now widely used in various industries, including in the oil and gas complex. This article discusses the history of the emergence and development of single-screw hydraulic machines (pumps and hydraulic motors), the structural and kinematic features of their working bodies, characteristics and advantages over other types of volumetric and dynamic machines. The main applications of single-screw hydraulic machines in the oil and gas industry for well drilling and mechanized production are presented. The prospects of this type of equipment in innovative technological projects and ways to improve their designs are noted.

Keywords: Moineau; Cycloidal gearing; Progressive cavity pump; Downhole displacement motor; Working bodies

\section{Review}

Among the various equipment used both in general engineering and in the oil and gas complex, a prominent place (in design and engineering solutions, research and development approaches, product range, total energy costs) is occupied by hydraulic machines, without which it would be impossible for many modern technological processes.

One of the promising types of hydraulic machines, which are becoming more widespread in many industries, are single-screw machines belonging to the class of rotary volumetric machines. Nowadays, when single-screw pumps and hydraulic motors are widely used in all industrialized countries, few think about the history of the appearance and development of these machines.

Prototype screw pumps have a long history dating back to the ancient civilization of Mesopotamia. About 250 years before our era, the great Greek scientist Archimedes invented a water-lifting machine, which went down in the history of technology as an Archimedes screw. Its action is based on the use of gravity and the properties of a helical surface. The screw located in the tray is installed obliquely and is immersed in water at one end. The angle of inclination of the screw is selected less than the angle of elevation of the helix. Under this 


\section{Petroleum \& Petrochemical Engineering Journal}

condition, the withdrawn portion of water during rotation of the screw progressively moves from bottom to top by 3-4 m.

Only after two millennia, the principle of the Archimedean screw was transformed into a volumetric (hydrostatic) pump. This was accomplished by the French engineer Rene Moineau (1887-1948), who proposed a fundamentally new scheme of a rotary volumetric hydraulic machine, laying in it the fundamental principle of "capsulism" [1].

This principle, which has become an innovation in the theory and practice of screw machines, consists in the use as working bodies (WB) of only two screw parts with cycloidal engagement - the rotor and stator, which acts as a contactor (which in other devices is designed as an obligatory additional part) and radial supports. This greatly simplified the design of the WB and allowed the creation of a variety of schemes for hydraulic machines and compressors with different kinematic ratios (number of runs) and layout (with a fixed stator, with a fixed rotor, with the mobility of both parts, etc.). This design of WB allows one of the paired parts (stator) to be made with an elastic coating, which significantly expands the scope of such machines when using almost any liquids and mixtures.

The combination of the new principle of operation and design innovation (the implementation of the internal helical surface of the stator from elastomer) ensured the versatility of using the hydraulic machine in various working environments and operating conditions. In addition, this design feature simplifies the stator manufacturing technology, compensates for errors in the engagement of the $\mathrm{WB}$ and allows you to adjust the sealing ability of the WB by creating an interference fit.

Thus, the principle of capsulism, proposed by Moineau and implemented in a screw gerotor mechanism with internal cycloidal engagement, consists in creating sealed helical volumes (capsules) formed between the surfaces of the rotor and stator, which are theoretically sealed from the suction and discharge chambers.

In a modern interpretation, the implementation of the Moineau capsule principle is achieved by fulfilling five conditions that turn a simple screw pump, for example, an Archimedean screw, into a volumetric hydraulic machine: 1) The number of lobes of the stator and rotor should differ by one: $z_{1}=z_{2}+1$;

Baldenko DF and Baldenko FD. Single-Screw Hydraulic Machines in the Oil and Gas Industry: Fields of Application and Development Prospects. Pet Petro Chem Eng J 2019, 3(5): 000207.
2) The screw surfaces of the stator and rotor must have the same direction (right or left);

3 ) The steps of the screw surfaces of the rotor and stator should be proportional to their number of lobes;

4) The length of WB must be at least one pitch of the stator;

5) The profiles of the rotor and stator must be mutually flexible and be in continuous contact during engagement.

The first R. Moineau patent took priority on May 1930 and protected a device that can be used as a pump, motor, compressor, or mechanical transmission [2]. This patent marks the birth of a new principle for volumetric hydraulic machines.

In Figure 1 shows the WB of a pump with a single-lobe rotor $\left(z_{2}=1\right)$ in longitudinal and transverse sections. Three types of chambers are formed between the screw surfaces of the WB: suction chambers, sluices (capsules) and pressure chambers. When the rotor rotates clockwise, the fluid moves from left to right, and when the rotor rotates in the opposite direction, from right to left.

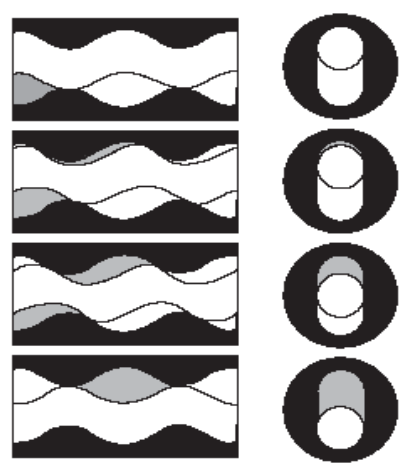

Figure 1: The working bodies of the Moineau pump (in different phases of the rotor position in the stator when turned through an angle of $180^{\circ}$ ).

The working process of the volumetric pump consists in the fact that when the rotor is rotated, the chambers open at one end of the WB expand, close (becoming isolated) and transfer to the other end, decreasing in volume and disappearing. At a fixed point in time (with the rotor conditionally stopped), the position of the chambers and their area change along the length of the WB (Figure 1). 


\section{Petroleum \& Petrochemical Engineering Journal}

Due to the indicated structural and kinematic features, single-screw pumps, referred to in the technical literature as the progressive cavity pump (PCP), combine the positive qualities of dynamic and volume hydraulic machines with important operational advantages that distinguish them from other types of pumps.

\section{Compared To Dynamic Pumps:}

1. Independence of the generated pressure from the rotational speed of the drive shaft, which extends the range of PCP use in terms of drive speed;

2. A relatively low fluid velocity in the flow part of the pump (2-3 times less than in a centrifugal pump of the same dimensions), which increases the durability of the flow part of the PCP, since the intensity of hydroabrasive wear is proportional to the speed cube;

3. High suction capacity.

\section{Compared to Reciprocating Pumps:}

1. The absence of valves or other distribution devices, since the distribution of fluid is ensured automatically due to the fundamental relationships between the geometric parameters of the screw surfaces of the WB;

2. Lack of dead space of working chambers;

3. Almost uniform (without ripple) feed proportional to the rotational speed;

4. The ability to change the direction of fluid movement by simply reversing the drive shaft;

5. Continuous change of position of contact lines of WB;

6. Reduction of metal consumption of the design and dimensions of the pump;

7. High speed PCP with a single-lobe rotor, which allows (as for centrifugal pumps) to connect them directly (without reducing devices) with electric motors having a speed of 1000-3000 rpm.

The main advantage of PCP, which determined their wide distribution in various fields of technology, is the ability to pump almost any type of liquid, including highly viscous ones containing gas and solid inclusions, as well as multiphase mixtures.

Compared with the closest in design and operation principle, two- and three-screw pumps, the PCP are different: the minimum diametrical dimensions of the WB (due to internal gearing and the absence of contactors); simplicity of design of body parts; lack of a synchronizing gear; the presence of an elastic element in the WB (which expands the ability to control pressure characteristics by changing the diametrical interference in the pair and reduces the requirements for the accuracy of manufacturing WB). The scope of any type of pump is characterized by supply and pressure fields, properties of the pumped liquid (density, viscosity, temperature, chemical aggressiveness, gas and particulate matter content), design and operational features (stationary, mobile, ground, well pumps, etc.).

The supply and pressure fields $Q$ - $P$ of single-screw pumps for general and special purposes are distributed in feeds from 0.001 to $150 \mathrm{l} / \mathrm{s}$ and in pressures up to 30 MPa.

According to the generalized criterion-pump specific speed $N s$, single-screw pumps are in the range $N s=2-20$, which means that PCPs have the highest specific speed among volumetric pumps (for three-piston pumps $N s=$ $0.05-2)$ and together with vortex pumps (Ns = $13-40)$ occupy the boundary region between volumetric and dynamic $(N s=40-170)$ pumps.

For dynamic and rotary pumps, there is one and the same pattern of structural change with increasing Ns: the radial direction of flow (in centrifugal, vane and gear pumps) goes into axial (axial, screw pumps). In a comparable $Q-P$ field, single-screw pumps have a higher efficiency than vortex or multi-stage centrifugal pumps. Compared with piston pumps, PCPs have smaller dimensions and weight.

One of the main advantages of PCP is the ability to pump almost any liquid in a wide range of changes in their density and viscosity (up to $12000 \mathrm{cP}$ ). Only piston pumps, which are much more complex in design, expensive to manufacture and metal-intensive, can be compared with PCP in terms of universality of use.

The presence of an elastic cage allows the wide use of PCP for pumping contaminated liquids, while centrifugal and piston pumps for pumping liquids with suspensions have special design modifications. The industrial catalogs of leading engineering companies (Netzsch, PCM, Seepex, Schlumberger, Weatherford, Livgidromash, etc.) indicate up to 300 types of liquids, emulsions, pastes, and other media that are effectively pumped by PCP.

\section{Main Applications of PCP}

1. Lifting oil and formation fluids from wells using rodless and sucker rod pumping units;

2. Technological processes in various industries; 


\section{Petroleum \& Petrochemical Engineering Journal}

3. Water raising, land reclamation and irrigation in agriculture;

4. Water supply in utilities;

5. Pumping of various products in the food and wine industry;

6. Emptying of tanks, tanks and other containers;

7. Pumping water from mines and mine workings;

8. Transportation of mortars and paints:

9. Innovative energy and environmental technologies.

In Europe, the first pumps for oil production were introduced in the 1980s by the French Petroleum Institute (IFP) and Total. Simplicity of operation and configuration, low costs and a wide range of fluid properties are the basis for the success of Moineau pumps in the oil industry.

Among the new technological advances, it is worth paying attention to the patented all-metal PCM Vulcain pump for the production of viscous oil by thermal stimulation of the formation (CSS, SAGD). The unique technology created allows us to manufacture stators from metal, while maintaining all the necessary geometric and hydraulic characteristics to achieve high performance in operation and pump quality. Vulcain pumps are successfully used in a number of countries in America and Europe, in particular when operating high-viscosity oil and natural bitumen deposits.

In Russia, a large amount of development work was carried out in the 1960-70s at the Special Design Office for Rodless Pumps (OKB BN), where for the first time in world practice submersible screw electric pumps for oil production and water lifting were developed and introduced. In the 1980-90s, PCR with multi-lobes working bodies were developed at the VNIIIBT and the Gubkin State University of Oil and Gas, which made it possible to increase the efficiency of the use of pumps in various technological processes. Over the years, many experts in different countries conducted theoretical and experimental studies that laid the foundations of the theory of the PCP workflow, methods for their design and operation [3-8].

Particularly intensive development of the PCP was in the oil industry, which is associated with an increase in oil production and the complication of field operating conditions (an increase in the share of the mechanized production method, a decrease in the average production rate of wells, an increase in the viscosity of the reservoir fluid, as well as the content of free gas and solids in it).
A new page in the development of single-screw hydraulic machines has opened in connection with the proliferation of drilling technologies using hydraulic downhole motors. Work on the creation of volumetric hydraulic motors based on working bodies designed according to the Moineau principle (in the West they are designated as PDM - Positive Displacement Motors) began almost simultaneously in the USA (Smith Tool) and the USSR (VNIIBT) and in the 60s of the last century.

Initially, a different approach to the designation of these machines was outlined: in the USSR, the hydraulic motor was developed as a replacement for the low-speed rotary method of driving rock cutting tools, while in the USA as an alternative to the turbine method of drilling. Hence the fundamental difference in the design of the working bodies of the motor. In the USSR, a scheme with multiple profiles of the WB was adopted (Figure 2), and in the USA they used the general scheme of the motor as a Moineau reversed pump with a single-lobe rotor.

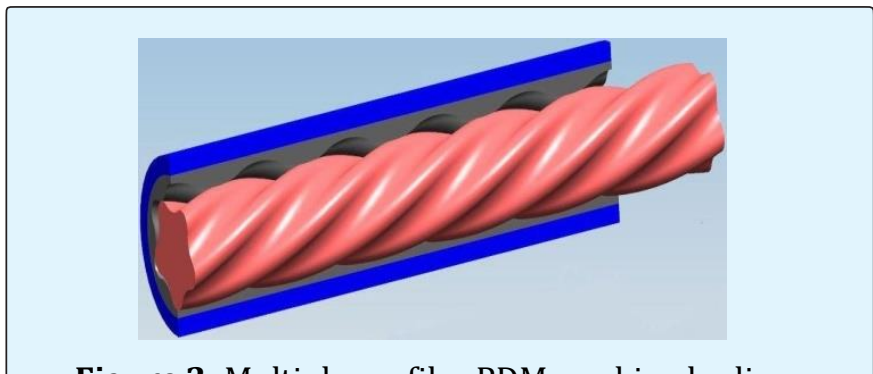

Figure 2: Multiple profiles PDM working bodies.

It turned out that in addition to generating power on the output shaft, the multi-lobe gerotor mechanism with cycloidal gearing also performs the functions of a planetary gearbox, the gear ratio (multiplicity of action) of which is equal to the number of rotor strokes (Figure 3), which made it possible to construct a gamma of motors with different torque and speed.

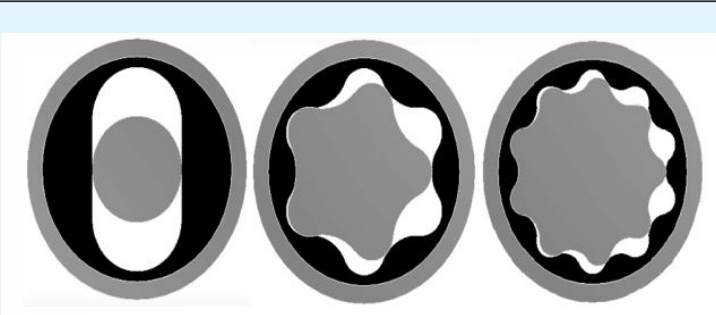

Figure 3: Cross sections of PDM with different kinematic ratio $(1: 2 ; 5: 6 ; 9: 10)$. 


\section{Petroleum \& Petrochemical Engineering Journal}

Fundamental theoretical and experimental studies of the PDM workflow and the creation of a set of technological equipment for the manufacture of multilobes working bodies [9-11] provided optimal energy and operational characteristics of these hydraulic machines for various conditions of their operation in drilling and overhaul of oil and gas wells. Due to the limitations of the invention of the optimal geometry of multi-lobes WB, as well as the Moineau principle, screw hydraulic machines are the property of all mankind and have been adopted by many oil engineering companies in the world.

Currently, PDM has become one of the main technical means for driving rock cutting tools and is the basic design for innovative drilling technologies, such as directional and horizontal drilling, sidetracking, motorized rotary diverter systems, casing drilling, etc.

What factors contributed to the widespread adoption of PDM:

firstly, due to the special tribological characteristics of the working bodies (a combination of sliding and rolling) and the presence of an elastic lining of the stator, it becomes possible to use practically all the solutions used in drilling as a working fluid; secondly, the unique energy and operational characteristics of PDM (high torque at a low speed, linear relationship between torque and pressure drop, minimum axial clearance, the ability to adjust technical parameters by changing the interference fit and elastomer properties, simplified assembly and adjustment scheme compared to downhole motors of a different type).

Summing up the development of drilling equipment and technology, the authoritative international journal Oil \& Gas classified multi-lobes PDMs as one of the outstanding achievements of drilling equipment in the second half of the 20th century. The importance of PDM for the modern oil and gas industry can be judged even by the fact that, for example, in Russia PDMs provide more than $75 \%$ of the volume of drilling work in well construction and almost $100 \%$ of work in the overhaul of oil and gas wells.

In addition, the cycloidal engagement embedded in the screw gerotor mechanism, given the wide range of gear ratio and tooth numbers (starting from 1-3, which is unattainable for other types of gears), can be considered as a very promising direction of development of gear mechanisms (with internal and external gearing, as well as planetary type, Figure 4) for various branches of mechanical engineering [12].

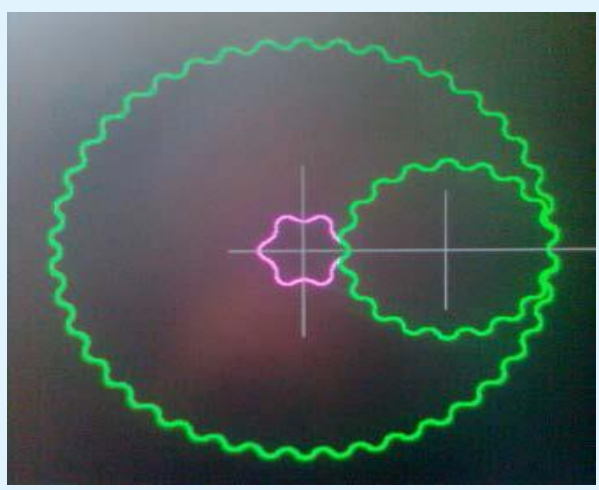

Figure 4: Planetary gearbox with cycloidal tooth profile (scheme 6-18-42).

Thus, the basic principles laid down in the creation of single-screw hydraulic machines were embodied in all industries, including the most important areas of the oil and gas complex, related to mechanized oil production and drilling of oil and gas wells.

It can be assumed that in the future, as the oil and gas industry develops and the field development conditions become more complicated, single-screw hydraulic machines will continue to improve and remain an indispensable technical tool that ensures the progress of the oil and gas and energy complex [13]. Research and development work show that in addition to the traditional fields of application of single-screw hydraulic machines, there are the following promising areas for creating machines based on cycloidal screw working bodies for drilling and oilfield equipment:

In drilling: bottom rotators of the drill string, BHA oscillators, mobile mud pumps, planetary gear drives for drilling rigs and downhole motors.

In oil production: hydraulic borehole screw pumping units, multiphase pumping systems.

Ways of further improvement of single-screw machines are associated with modifying the geometry of cycloidal engagement, constructive optimization of loaded elements and assemblies based on computer technology and three-dimensional modeling, selection of materials and methods for hardening work surfaces, improving 


\section{Petroleum \& Petrochemical Engineering Journal}

manufacturing quality using innovative gear processing centers.

\section{References}

1. Moineau JL, Rene Moineau (2009) Aviator and inventor. Editions de, officine Paris.

2. Moineau RLJ (1930) Pompe France Patent.

3. Noscievic J (1961) Vretenova Cerpadla. Praha, SNTL.

4. Krylov AV (1962) Single-screw pumps. Moscow, Gostoptekhizdat.

5. Baldenko DF, Bidman MG, Kalishevsky VL (1982) Screw pumps. Moscow, Mashinostroenie.

6. Revard JM (1995) The progressing cavity pumps handbook. PennWell Publishing Company, Tulsa, USA.

7. Cholet H (1997) Progressing cavity pumps. Editions Technip, Paris.
8. Nelik L, Brennan J (2005) Progressing Cavity Pumps and Mudmotors. Gulf Publishing Company, Houston.

9. Gusman MT, Baldenko DF, Kochnev AM, Nikomarov SS (1981) Downhole screw motors for drilling wells. Moscow, Nedra.

10. Baldenko DF, Baldenko FD, Gnoevykh AN (2007) Single-screw hydraulic machines (in two volumes). Moscow, IRC Gazprom.

11. Samuel R, Baldenko DF, Baldenko FD (2015) Positive Displacement Motor: Theory and Applications. Sigma Quadrant Publisher.

12. Baldenko DF, Baldenko FD (2019) On the choice of the profile of teeth mechanical transmissions and hydraulic machines. Moscow: Scientific Magazines, Drilling and Oil, pp: 3.

13. Electronic resources of firms: Netzsch, PCM, Schlumberger, Seepex, Weatherford, NPO Drilling Technics, Livgidromash, etc. 